\title{
Palavras e silêncios na educação superior em odontologia
}

\author{
Words and silence in \\ the dentistry education
}

Maria Ercilia de Araujo ${ }^{1}$

\begin{abstract}
The debate around academic education includes nowadays the professional profile provided by the University. In the same sense, this article approaches the necessary review of the programs for formation of professionals in the Brazilian schools of odontology. This formation must have a direct interface with the real necessities of the population in terms of oral health and has to be inserted in the paradigm of the National Public Health Policy and the principles of the National Unified Health System (SUS-Sistema Único de Saúde). In order to reach this goal, teaching skills and educational concepts must be reviewed for allowing students to be active agents of their formation, with a critical perspective of their own professional practice.
\end{abstract}

Key words Higher education in odontology, Teaching in odontology, Oral health
Resumo O debate sobre a formação universitária passa, atualmente, pelo perfil de profissional que esta sendo formado nas universidades. Este artigo considera, nesta mesma direção, a necessidade de uma revisão na formação dos profissionais nas faculdades de odontologia do Brasil. Esta formação deve estar em interface direta com as reais necessidades de saúde bucal da população, e inserida no paradigma da política pública de saúde e dos princípios do Sistema Único de Saúde. Para se atingir tais objetivos, a capacitação docente deve passar por um processo de revisão de conceitos educativos, que permitam ao aluno se tornar um agente ativo no processo de ensino, com perspectiva crítica em relação à sua própria prática profissional.

Palavras-chave Educação superior em odontologia, Ensino odontológico, Saúde bucal
1 Departamento de Odontologia Social da USP. Av. Prof. Lineu Prestes 2227, Butantã, 05508-000, São Paulo SP. mercilia@usp.br 
A minha boca e a tua vão

deixando pela rua

Palavras e silêncios que jamais

se encontrarão.

Zeca Baleiro

Antes de decidirmos pelo tipo de universidade que queremos edificar, é necessário refletir sobre o modelo de sociedade que desejamos desenvolver. ${ }^{1}$

Vivemos hoje um processo de esgotamento do modelo tradicional de educação superior. A necessidade de mudanças dessa formação tem estado na pauta das discussões há algum tempo, e pouco se tem avançado.

A questão da formação de profissionais de saúde envolve diretamente as oportunidades advindas do mercado de trabalho, o perfil profissional e a satisfação das demandas populacionais. Assim, a articulação entre as políticas de educação e de saúde é fundamental para que as transformações sejam possíveis.

É necessário situar o verdadeiro papel da educação superior para a formação de recursos humanos vinculados ao sistema de saúde brasileiro, locus da aplicação da chamada saúde bucal coletiva. Aqui cabe uma observação: esse sistema de saúde deve ser entendido como sendo de toda a população, e não somente dos pobres, já que, por exemplo, a cada vez que os honorários médicos são deduzidos do Imposto de Renda ou é fornecido recibo aos pacientes também com a renúncia fiscal dos planos de saúde suplementar - ou, ainda, a cada vez que se abrem as torneiras de água de abastecimento público, está se fazendo uso desse sistema.

A relação da academia com a sociedade deve ser reorientada. Ao analisarmos as funções básicas da universidade, deparamo-nos com a seguinte situação: o ensino que recebe a maior parte das energias e recursos nutre-se, principalmente, de conhecimentos que vêm de outros países e que têm pouca relação com os problemas da nossa sociedade; a pesquisa estuda problemas relativamente superficiais, com pouca ou nenhuma participação das comunidades a que se destinam, quando têm destinação social; e a extensão universitária passa como que à margem do sistema universitário e do sistema de saúde, levando à comunidade, de forma paternalista e unilateral, os resíduos das preocupações universitárias.

Dessa forma, é natural que o ensino se dê por uma orientação "bancária", conforme classifica Paulo Freire2 ${ }^{2}$ em que meramente se transmite o conhecimento, esperando que os alunos façam as correlações necessárias entre o referencial teórico e a práxis, entre a academia e a sociedade.

Nestes tempos de novas relações, deve-se ter a extensão como objetivo básico da educação superior, redefinida e ampliada como "promoção da comunidade”, necessariamente multidisciplinar, buscando a transdisciplinaridade. Isso deve ser efetuado numa ação da universidade em associação com a população, para resolver os problemas prioritários e transformar a sociedade atual em uma sociedade mais justa e solidária. Desse modo, a pesquisa deve buscar diagnosticar e propor soluções para os problemas, de maneira mais ampla, não se fechando em guetos, "da saúde”, "da educação", "da segurança", "da habitação", "do meio ambiente”, mas de maneira intersetorial. Em suma, a função do ensino deve ser capacitar docentes, alunos e grupos da comunidade para debater as questões consideradas mais fundamentais e, a partir disso, aplicar as soluções encontradas.

Ainda assim, a universidade não deve substituir as instituições oficiais, mas atuar de maneira compartilhada, propondo e agindo de acordo com as pactuações firmadas entre as comunidades, as instâncias oficiais e a academia.

Por outro lado, é necessário refutar as noções cada vez mais estereotipadas de formação da educação superior, como se fosse ético e correto formar profissionais de segunda classe, quando a premissa deve ser formar profissionais de acordo com as necessidades regionais. Quando se propõe uma formação para os profissionais do Sistema Único de Saúde-SUS, e outra, mais competente, para as clínicas especializadas ou científicas, a fim de capacitar profissionais diferentes daqueles que irão atuar na saúde da coletividade - tão necessários para sustentar a eficiência e a eficácia na ponta do sistema de saúde, no nível primário e secundário ${ }^{3}$-, configura-se um grande passo a caminho do abismo da exclusão social. Mais abrangente do que abordar os referenciais da saúde coletiva, é aprofundar os princípios sobre o tipo de saúde que estamos oferecendo para a coletividade.

Esse processo deve ultrapassar o campo da saúde bucal coletiva, estendendo-se para todas as áreas, acabando com as dicotomias entre básico e clínico, entre clínico e social e entre público e acadêmico.

A educação superior deve assumir a formação de competências para atuar nesse novo contexto, preparando o profissional para a construção do seu conhecimento, conduzindo, de ma- 
neira contínua, em direção a uma formação integral.

Moacir Gadotti, ao prefaciar obra de Freire $^{2}$, afirma que toda educação é sempre um ato político, no sentido de que a sua relação com o poder decorre do domínio do conhecimento, e os que sustentam o contrário estão defendendo a política da despolitização. Afirma, ainda, que no Brasil a educação sempre esteve a serviço das classes dominantes e que embora a educação tenha ignorado a política, a política jamais ignorou a educação. E quanto ao compromisso do profissional com a sociedade, Freire 4 propõe que a capacidade de ação e reflexão são fundamentais para propiciar a capacidade crítica do educando.

O conhecimento gerado no século 20 foi substituído pelo ensino fragmentado e visual. A interdisciplinaridade se coloca como uma possibilidade de se corrigir distorções provocadas pelo excesso das especializações e sua conseqüência - a fragmentação do conhecimento.

A relação existente entre saúde e educação diz respeito à adequação dos profissionais às necessidades sociais da população. Essa relação será obtida pela efetiva interação entre a formação dos profissionais de saúde, os serviços de saúde do SUS e as comunidades, constituindo uma importante estratégia para promover as mudanças necessárias na formação acadêmica. Neste cenário, a odontologia como profissão tem-se mostrado ineficiente nas suas ações, apesar de não ter ficado à margem das transformações vividas pelos sistemas de saúde nas últimas décadas ${ }^{5}$. A prática atual da profissão é fruto da exaustiva ênfase dada ao caráter individualista que caracterizou a odontologia desde o seu início.

Ao refletirmos sobre a saúde bucal coletiva, podemos verificar que os conhecimentos e os conceitos advindos das ciências sociais têm ajudado a odontologia a se aproximar de uma realidade que faz parte de outra lógica, tornando possível identificar e compreender os aspectos sociais, suas repercussões na maneira das pessoas "de estar no mundo" e, conseqüentemente, de influenciar no processo saúde-doença.

Esses conhecimentos são parte do instrumental necessário para se levar em conta o conteúdo em que as pessoas vivem e para entendê-las em suas múltiplas dimensões, o que é importante no momento de estabelecer relações, interpretar situações, analisar causas e propor soluções para os seus problemas. Entretanto, a estratégia de inserir essas ciências co- mo disciplinas revelou-se insuficiente, pois a sua capacidade de formação é limitada, não conseguindo influir no núcleo duro da formação em saúde 3 .

Para Formicola 6 , a grande falha do ensino odontológico é resultante da crença de que este não pode ser cientificamente embasado e socialmente científico ao mesmo tempo, estabelecendo-se um descompasso entre esses dois movimentos, sem possibilidade de harmonia.

Os processos profundos de transformação na formação de recursos humanos são complexos, envolvem mudanças conceituais, de relações institucionais, de enfrentamento de conhecimentos e valores, cristalizados e hegemônicos, e a construção de uma nova ordem. São processos que implicam em conflitos e pressões, e que demandam um longo tempo de maturação, construção e avaliações periódicas7.

Por outro lado, os métodos fascinam, mas, como afirma Bourdieu8, a modernização dos métodos não garante por si só que a universidade se integre ao seu meio, identifique-se com seus problemas e influa para mudar a realidade social. É necessário tratar, especificamente, da questão da mudança do conteúdo e das práticas. Estas não são decorrência automática de qualquer mudança metodológica, mas demandam uma transformação na cultura pedagógica da instituição, com um processo de capacitação em educação para docentes que, historicamente, eram "bons mestres" por serem "bons técnicos".

A saúde deve ser o eixo que orienta a estruturação curricular, encetando a formação de um profissional apto a interferir na realidade do indivíduo e da comunidade, buscando a sua transformação. A educação do profissional também não pode se encerrar com a conclusão do curso, pois deve se manter numa continuidade durante toda sua vida. Assim, estudantes, professores, profissionais de saúde e usuários devem ser sujeitos dessa mudança, constituindo o processo coletivo de reflexão crítica sobre as práticas tradicionais, de aquisição de novos conhecimentos.

Dessa forma, as transformações não devem ser definidas a priori. Elas não se constroem simplesmente na prática pedagógica, no papel, em "ambientes especiais" (clínicas das faculdades odontológicas), mas em todos os cenários nos quais se dá a prática profissional, enfrentando os problemas que se apresentam nas realidades, permitindo a reflexão e propondo as mudanças necessárias para superar a nossa indignação cotidiana. 


\section{Referências}

1. Fernandes F. Reforma universitária e mudança social. São Paulo: Cortes; 1974.

2. Freire P. Pedagogia do oprimido. 17a ed. Rio de Janeiro: Paz e Terra; 1987.

3. Canesqui AM. Dilemas e desafios das ciências sociais na saúde coletiva. São Paulo: Hucitec; 2000.

4. Freire P. Pedagogia da autonomia. 29a ed. São Paulo: Paz e Terra; 2004.

5. Narvai PC. Recursos humanos em saúde. In: Kriger L, organizador. Aboprev: promoção de saúde bucal: paradigma, ciência e humanização. 3a ed. São Paulo: Artes Médicas; 2003
6. Fomicola AJ. The dental curriculum: the interplay of pragmatic necessities, national needs, and education philosophies in shaping its future. J Dent Educ 1991; 55(5):358-64.

7. Feuerwerker LCM. Além do discurso de mudança na educação médica: processos e resultados. São Paulo: Hucitec; 2002.

8. Bourdieu P. Razões práticas: sobre a teoria da ação. Campinas: Papirus; 1996.

Artigo apresentado em 5/07/2005

Aprovado em 30/08/2005

Versão final apresentada em 30/08/05 